\title{
The Effects of Group Exercise, Manual Therapy and Home Exercise on Pain, Range of Motion and Function in Patient with Adhesive Capsulitis
}

\author{
Kwag Kwang II', Seo Eun Kyoung², Kim Tae Yoon ${ }^{3}$ \\ 'Department of Sports Rehabilitation, WE Training Center; ${ }^{2}$ Department of Health Science, Graduate School of Chosun University; ${ }^{3}$ Department of \\ Physical Therapy, Wonkwang Health Science University
}

Purpose: The purpose of this study was to determine the effects of group exercise, manual therapy, and a home exercise program on VAS (visual analogue scale), ROM (range of motion) of shoulder, and functional outcome in adhesive capsulitis.

Methods: The study was conducted with 45 patients. All subjects were randomly assigned to 3 groups: group exercise $(n=15)$, manual therapy $(n=15)$, home exercise $(n=15)$. The subjects performed an intervention program 3 times a week for 4 weeks a total of 12 times. Outcome measurements were VAS, ROM, and Constant-Murley score outcome measures. Measurements were taken four times, at baseline, 4 weeks later, 8 weeks later, and 12 weeks later.

Results: VAS, ROM of the shoulder, and functional outcomes showed improvement in all groups at the final follow-up $(p<0.05)$. VAS and ROM showed greater improvement with group exercise and manual therapy than home exercise, however, there were no significant differences between the two groups $(p>0.05)$. Functional outcomes showed the greatest improvement in group exercise at the final follow-up. This improvement was greater than with manual therapy or home exercise $(p<0.05)$.

Conclusion: Group exercise and manual therapy were more effective for improving pain, ROM, and function than home exercise in adhesive capsulitis. In particular, group exercise is more effective in functional recovery than other physiotherapy interventions.

Keywords: Adhesive capsulitis, Group exercise, Manual therapy, Home exercise

\section{서 론}

유착성관절낭염(adhesive capsulitis)은 어깨관절의 내재적 질환 없이 통증과 능동적 및 수동적 관절운동 범위의 제한을 보이는 질환 ${ }^{1}$ 으 로, 대략 1-2년 정도의 기간이 지나면 자가 치유되는 질환으로 알려져 있다. 적절한 치료를 하지 않은 경우 유착성관절낭염 환자의 $40 \%$ 가 지속적인 통증 및 관절운동 범위가 제한되었으며, $11 \%$ 는 영구적인 어 깨 기능장애를 나타낸다는 보고도 있다. ${ }^{3}$

많은 선행연구에서 유착성관절낭염의 가장 효과적인 치료 방법을 수립하기 위한 노력들이 있어왔다. 기본 물리치료(therapeutic modalities)와 운동치료, 약물 및 주사치료 ${ }^{4}$, 수압팽창술 ${ }^{5}$, 마취하 도수조작 ${ }^{6}$ 과 같은 보존적 요법이 유착성관절낭염 치료의 주 원칙으로 통용되 고 있지만 7 환자가 장기간의 보존적 치료를 원하지 않거나 일정 기간 의 체계적인 치료에도 불구하고 회복 징후가 보이지 않을 때는 수술
적 접근이 고려되기도 한다. ${ }^{8}$ 그러나, 질병의 자연경과를 두고 보았을 때 수술적 고려가 필요한 것인지 의문이며, 증상 발현기간과 통증 양 상에 따라 보존적 치료의 선택에도 논란의 여지가 있다.

유착성관절낭염의 물리치료 중재방법으로 기본 물리치료와 도수 치료 그리고 능동 및 수동적 운동치료 등이 임상 현장에서 널리 사용 되고 있으며, 치료 방법의 선택과 적용은 다양한 방식으로 수행된 다. ${ }^{10,11}$ 유착성관절낭염의 주요 증상인 통증을 경감하고 관절 강직 (joint stiffness)에 따른 기능을 회복시키기 위해서는 상당한 시간이 소요된다. 따라서 환자의 치료에 대한 동기 부여 및 능동적인 의지가 예후에 많은 영향을 주게 된다. 최근 물리치료 중재방안으로 유착성 관절낭염 치료에 대한 근거중심의 임상지침들이 활발하게 논의 되고 있으나, 유착성관절낭염 물리치료의 표준 지침에 대한 근거가 부족 하다. ${ }^{12}$ 유착성관절낭염의 임상지침 권고안에 따르면 환자 스스로 증 상을 관리할 수 있는 능동적 운동프로그램의 적용을 강조하고 있다. 
결과적으로 근골격계 질환의 치료 방향이 수동적인 방법보다 능동 적인 치료의 중요성이 강조되는 것과 맥락을 같이 한다.13

본 연구의 목적은 선행 연구에서 제시된 임상지침을 근거로, 유착 성관절낭염 물리치료 중재방법으로 임상에서 주로 적용되는 능동적 인 그룹운동과 치료사의 수동적인 도수치료, 가정운동 프로그램을 적용하여 통증과, 견관절의 관절가동범위, 견관절 기능에 미치는 영 향을 알아보고 유착성관절낭염 치료에 유용한 임상적 자료를 제공 하는 데 목적이 있다.

\section{연구방법}

\section{1. 연구대상}

본 연구는 3 가지 주요 물리치료 중재방법에 대한 치료 효과를 비교하 기 위해 무작위 통제실험을 실시하였다. 대상자 선정은 J도에 소재하 고 있는 관절전문병원에서 입원 및 외래 치료를 받고 있는 환자들로 하였다. 기관생명윤리위원회(IRB NO. 2014-12-019-003)의 심의를 거 쳐 연구 승인을 받은 후 모든 대상자들은 실험 제반절차에 따른 주의 할 점에 대해서 충분한 설명을 듣고 자발적으로 연구 참여 의사에 동 의하고 서명하였다. 대상자의 선정 조건은 유착성관절낭염 진단을 받은 환자들을 대상으로 별도로 적합 기준과 제외 기준을 마련하였 다. 적합 기준으로 어깨 관절운동 범위의 감소와 통증이 자연 발생한 경우, 방사선(X-ray) 검사상 특이 소견이 없으며, 정상측 외회전 및 내 회전 범위의 $50 \%$ 미만 제한 등의 유착성관절낭염의 전형적인 특징으 로 정하였다.14 또한, 유착성관절낭염의 초기 "통증 우세"에 해당하는 환자들을 최소화하기 위해 최소 3 개월 이상의 증상을 지속하는 대 상자들로 하였다. 제외 기준으로는 지난 3 개월 동안 손상 측 어깨에 주사치료나 물리치료를 받은 경우, 손상 측 어깨에 회전근개 손상, 골 절, 수술을 받은 경우, 경추 질환이 명백하거나 전신성 질환이 있는 경우로 정하였다. 모든 대상자들에게 약물을 제외하고 실험기간 동 안 다른 보조적 치료를 받지 않도록 요청하였으며, 각 치료군의 대상 자들이 일주일 이상 중재프로그램에 참여하지 못할 경우에는 실험 에서 제외하였다.

유착성관절낭염 진단을 받은 60 명의 환자가 최종 모집되었으며, 이 들 가운데 2 명은 일차성 유착성관절낭염의 적합 기준에 맞지 않았 고, 2 명은 참여 포기 의사를 나타냈다. 전체 56 명의 대상자를 세 군의 물리치료 중재군에 무작위로 배정하였으며, 실험을 진행하는 동안 추가로 11 명의 탈락자가 발생되어 최종 실험에 참여한 대상자는 총 45명이었다.

\section{2. 실험방법}

본 연구는 2015년 2월 17일부터 대상자 모집을 실시하여 2주간의 예
비 실험을 실시하여 실험 절차와 문제점을 수정 보완 후 2015년 3월 부터 5월까지 본 실험을 실시하였다. 대상자 선정기준에 적합한 환자 들은 무작위로 세 군의 물리치료 중재군(그룹운동군, 도수치료군, 가 정운동군)에 할당되었다. 그룹운동군은 기본 물리치료와 그룹운동 (짐볼운동, 스톨바 운동, 견갑골설정운동, 흥추가동화운동, 견관절안 정화운동)을 주 3 회, 각 운동별로 5 분씩 시행하였다. 도수치료군은 기본 물리치료와 주요 도수치료 방법을 적용하였는데, 기능적 마사 지와 신장운동은 극상근, 극하근, 소원근, 견갑하근, 대원근, 대흥근 및 승모근 상부섬유에 통증감소와 조직 이완시까지 적용하였고, 관 절가동화기법은 관절와상완관절에 하방 및 후방활주, 외측견인을 적용하고, 흥추에는 굴곡 및 신전가동화운동을 시행하였다. 그룹운 동군과 가정운동군은 어깨 재활운동 경력 5년 이상의 전문치료사 3 명이 교대로 운동 지도와 교육을 담당하였고, 도수치료군은 10 년 이 상의 임상 경험이 있는 정형도수치료사가 전담하였다. 치료는 일주일 에 3 회씩 4 주 동안 총 12 회 시행하였으며, 이후부터 모든 군은 가정운 동 프로그램을 지속하도록 하였다. 실험 전과 실험 후 4 주, 8 주, 12 주 각 시기별로 임상적 결과를 측정하였다.

\section{3. 측정도구}

\section{1) 통증 척도}

통증 척도는 시각적 상사척도(visual analogue scales)를 이용하여 측정 시기별로 평가하였다. 시각적 상사척도 평가에서 최고치를 10 , 최소 치를 0 으로 하였다. ${ }^{15}$

\section{2) 견관절 가동범위}

관절운동 범위는 표준화된 검사 방법으로 측각기(Goniometer)를 이 용하여 바로선자세에서 능동 전방굴곡과 옆으로 누운자세에서 능 동 외회전, 능동 내회전의 운동범위를 측정하였다. ${ }^{4}$ 모든 관절운동범 위는 총 3 번을 반복하여 측정한 값의 평균을 구해 평가하였다.

\section{3) The Constant-Murley (Constant) score}

Constant score 는 어깨 질환에 대한 기능적 상태를 평가하는 데 흔히 사용되고 있으며, 비교적 높은 정확도와 신뢰도 및 재현성을 보여준 다. ${ }^{16}$ 주관적 지수와 객관적 지수를 합산하여 총 100 점으로 측정하며, 일상활동, 관절운동범위, 통증 및 근력의 4 가지 항목으로 구성되어 있다. 임상적으로 중요한 점수 변화의 판정 기준은 약 15 점으로 정하 고 있다

\section{4. 자료분석}

모든 자료는 SPSS PASW 18.0 Windows 를 이용하여 분석을 하였다. 정규성 분포는 Shapiro-Wilk 검정으로 확인되었다. 대상자의 일반적 
특성은 $\chi^{2}$ 검정과 One-way ANOVA를 실시하였고, 각 물리치료 중재 방법들의 치료 효과 및 시기별 차이를 비교 분석하기 위하여 반복측 정 이요인 분산분석(repeated measures two-way ANOVA)을 실시하였 다. 각 물리치료 중재군에 유의한 주 효과에 대하여 Bonferroni 검정 법으로 사후분석을 수행하였다. 모든 검정에서 통계학적 유의수준 $\alpha$ $=0.05$ 로 설정하였다.

\section{결 과}

\section{1. 연구 대상자의 일반적 특성}

대상자는 총 45 명이 참가하였다. 그룹운동군은 14 명(남성 4 명, 여성 10 명)이었으며, 평균 나이는 $51.1 \pm 6.8$ 세, 증상 지속기간은 $6.2 \pm 2.1$ 개 월, 우세팔에 $85.7 \%$ 가 이환된 것으로 나타났고, 도수치료군은 16 명(남 성 5명, 여성 11 명)이었으며, 평균 나이는 $51.1 \pm 6.5$ 세, 증상 지속기간은 $6.3 \pm 2.1$ 개월, 우세팔에 $75 \%$ 가 이환되었다. 가정운동군은 15 명(남성 5 명, 여성 10 명)이었으며, 평균 나이는 $53.7 \pm 4.7$ 세, 증상 지속기간은 5.7 \pm 2.1 개월, 우세팔에 $73.3 \%$ 가 이환되었다. 각 군 간 성별 분포, 평균 나 이, 증상 지속기간, 우세 측 어깨 관련 요인은 통계학적으로 유의한 차이가 없었다 $(\mathrm{p}>0.05)$.

\section{2. 통증}

통증 척도를 나타내는 VAS score 는 최종 12주 추시 결과에서 세 군 모두 유의하게 향상되었다. 치료 후 4주부터 그룹운동군과 도수치료 군은 가정운동군보다 통증 척도가 더 빠르게 감소하였으며, 최종 추 시 결과에서도 가정운동군은 $2.40 \pm 0.63$, 그룹운동군은 $1.79 \pm 0.42$, 도수치료군은 $1.69 \pm 0.47$ 으로 나타나 군 간 유의한 차이가 있었다 $(\mathrm{p}<0.05)$. 그룹운동군과 도수치료군은 최종 추시 결과에서 두 군 사 이에 유의한차이가 없었다 $(\mathrm{p}=0.999)$ (Table 1).

\section{3. 견관절 가동범위}

어깨 전방굴곡 각도는 최종 12 주 추시 결과에서 세 군 모두 유의하게 향상되었다. 치료 후 4주부터 그룹운동군과 도수치료군은 가정운동 군과 비교하여 어깨 전방굴곡 각도가 더 빠르게 증가하였다 $(\mathrm{p}<0.05)$. 그러나, 최종 추시 결과에서 그룹운동군은 $162.1 \pm 9.3$, 도수치료군은 $158.7 \pm 7.1$, 가정운동군은 $155.0 \pm 9.8$ 으로 나타나 세 군 사이에 유의한 차이가 없었다 $(\mathrm{p}=0.104)$ (Table 2).

어깨 외회전 각도는 최종 12 주 추시 결과에서 세 군 모두 유의하게 향상되었다. 치료 후 4 주부터 그룹운동군과 도수치료군은 가정운동 군과 비교하여 어깨 외회전 각도가 더 빠르게 증가하였으며, 최종 추 시 결과에서도 그룹운동군은 $53.9 \pm 7.1$, 도수치료군은 $52.5 \pm 7.3$, 가정

Table 1. VAS score for each intervention group over time

\begin{tabular}{lcccccc}
\hline Group & Initial & 4 weeks & 8 weeks & 12 weeks & Time effects $p^{*}$ & ${\text { Group effects } p^{+}}_{\text {Time } \& \text { group p }}^{\ddagger}$ \\
\hline GE & $6.93 \pm 1.20$ & $2.64 \pm 0.92$ & $2.07 \pm 0.47$ & $1.79 \pm 0.42$ & $<0.001$ & $<0.001$ \\
MT & $7.13 \pm 0.80$ & $2.56 \pm 1.50$ & $1.94 \pm 0.68$ & $1.69 \pm 0.47$ & $<0.001$ & $<0.001$ \\
HE & $6.93 \pm 1.38$ & $4.60 \pm 1.05$ & $3.93 \pm 0.79$ & $2.40 \pm 0.63$ & $<0.001$ & \\
\hline
\end{tabular}

Values are Mean \pm SD or as otherwise indicated.

GE: group exercise, MT: manual therapy, HE: home exercise.

" $p$-values for with-in group comparisons at different evaluation times.

${ }^{+} p$-values for between-group comparisons at different evaluation times.

${ }^{\ddagger} \mathrm{p}$-values for time and group interactions.

Table 2. Range of Motion for each intervention group over time

\begin{tabular}{|c|c|c|c|c|c|c|c|c|}
\hline & Group & Initial & 4 weeks & 8 weeks & 12 weeks & Time effects $p$ * & Group effects $P^{+}$ & Time \& group $\mathrm{p}^{\ddagger}$ \\
\hline \multirow[t]{3}{*}{ FF } & GE & $92.5 \pm 16.6$ & $140.0 \pm 17.4$ & $152.8 \pm 12.5$ & $162.1 \pm 9.3$ & $<0.001$ & $<0.05$ & $<0.001$ \\
\hline & MT & $100.6 \pm 14.1$ & $138.4 \pm 14.6$ & $150.3 \pm 12.4$ & $158.7 \pm 7.1$ & $<0.001$ & & \\
\hline & HE & $96.6 \pm 13.1$ & $115.3 \pm 12.4$ & $133.0 \pm 11.6$ & $155.0 \pm 9.8$ & $<0.001$ & & \\
\hline \multirow[t]{3}{*}{ ER } & GE & $16.1 \pm 4.4$ & $45.0 \pm 10.1$ & $47.8 \pm 8.0$ & $53.9 \pm 7.1$ & $<0.001$ & $<0.001$ & $<0.001$ \\
\hline & MT & $16.5 \pm 5.0$ & $45.6 \pm 10.7$ & $47.8 \pm 8.1$ & $52.5 \pm 7.3$ & $<0.001$ & & \\
\hline & $\mathrm{HE}$ & $18.0 \pm 6.4$ & $26.0 \pm 8.0$ & $30.6 \pm 7.5$ & $39.0 \pm 7.1$ & $<0.001$ & & \\
\hline \multirow[t]{3}{*}{$\mathbb{I R}$} & GE & $12.0 \pm 1.7$ & $15.3 \pm 0.9$ & $15.8 \pm 1.2$ & $17.2 \pm 0.9$ & $<0.001$ & $<0.001$ & $<0.001$ \\
\hline & MT & $11.3 \pm 1.1$ & $14.8 \pm 1.5$ & $16.0 \pm 0.7$ & $17.7 \pm 0.8$ & $<0.001$ & & \\
\hline & $\mathrm{HE}$ & $11.8 \pm 1.2$ & $12.7 \pm 1.8$ & $13.6 \pm 1.8$ & $14.8 \pm 1.3$ & $<0.001$ & & \\
\hline
\end{tabular}

Values are Mean \pm SD or as otherwise indicated.

GE: group exercise, MT: manual therapy, HE: home exercise, FF: forward flexion: ER: external rotation, IR: internal rotation

${ }^{*} \mathrm{p}$ values for with-in group comparisons at different evaluation times.

$p$ values for between-group comparisons at different evaluation times.

${ }^{*} \mathrm{p}$ values for time and group interactions. 
Table 3. Constant-Murley Score for each intervention group over time

\begin{tabular}{lllllcc}
\hline Group & Initial & 4 weeks & 8 weeks & 12 weeks & Time effects $p^{*}$ & ${\text { Group effects } \mathrm{p}^{+}}_{\text {Time } \& \text { group } \mathrm{p}^{\ddagger}}$ \\
\hline GE & $39.7 \pm 4.8$ & $71.2 \pm 10.1$ & $78.4 \pm 10.3$ & $83.7 \pm 9.8$ & $<0.001$ & $<0.001$ \\
MT & $37.2 \pm 9.9$ & $67.2 \pm 11.5$ & $71.1 \pm 8.7$ & $75.0 \pm 8.2$ & $<0.001$ & $<0.001$ \\
HE & $38.6 \pm 7.2$ & $47.5 \pm 8.0$ & $53.3 \pm 6.1$ & $57.7 \pm 7.1$ & $<0.001$ & \\
\hline
\end{tabular}

Values are Mean \pm SD or as otherwise indicated.

GE: group exercises, MT: manual therapy, $\mathrm{HE}$, home exercises.

" $p$-values for with-in group comparisons at different evaluation times.

$p$-values for between-group comparisons at different evaluation times.

${ }^{\ddagger} \mathrm{p}$-values for time and group interactions.

운동군은 $39.0 \pm 7.1$ 로 나타나 군 간 유의한 차이가 있었다 $(\mathrm{p}<0.05)$. 그 룹운동군과 도수치료군은 최종 추시 결과에서 두 군 사이에 유의한 차이가 없었다 $(\mathrm{p}=0.999)($ Table 2).

어깨 내회전 각도는 최종 12 주 추시 결과에서 세 군 모두 유의하게 향상되었다. 치료 후 4 주부터 그룹운동군과 도수치료군은 가정운동 군과 비교하여 어깨 내회전 각도가 더 빠르게 증가하였으며, 최종 추 시 결과에서도 그룹운동군은 $17.2 \pm 0.9$, 도수치료군은 $17.7 \pm 0.8$, 가정 운동군은 $14.8 \pm 1.3$ 으로 나타나 군 간 유의한 차이가 있었다 $(\mathrm{p}<0.05)$. 그룹운동군과 도수치료군은 최종 추시 결과에서 두 군 사이에 유의 한차이가 없었다 $(\mathrm{p}=0.999)$ (Table 2).

\section{Constant-Murley (constant) score 결과}

어깨 기능적 상태를 평가하는 constant 점수는 최종 12 주 추시 결과 에서 세 군 모두 유의하게 향상되었다. 그룹운동군과 도수치료군은 가정운동군과 비교하여 치료 후 4 주부터 constant 점수가 더 빠르게 향상되었으며, 최종 추시 결과에서도 그룹운동군은 $83.7 \pm 9.8$, 도수치 료군은 $75.0 \pm 8.2$, 가정운동군은 $57.7 \pm 7.1$ 로 나타나 군 간 유의한 차이 가 있었다 $(\mathrm{p}<0.05)$. 그룹운동군과 도수치료군은 모두 치료 후 빠른 constant 점수의 향상을 나타냈지만, 최종 추시 결과에서는 두 군 사 이에 유의한 차이가 있었다 $(\mathrm{p}=0.023)$ (Table 3).

\section{고 찰}

본 연구는 유착성관절낭염 치료에 주로 적용되고 있는 그룹운동치 료, 도수치료, 자가운동치료 중재방법의 임상적 효과를 비교하였다. 그룹운동군은 열, 전기치료를 포함하는 기본 물리치료와 자가 운동 치료를, 도수치료군은 기본 물리치료와 선택적 도수치료를, 가정운 동군은 기본 물리치료와 가정운동 프로그램을 각각 시행하였다.

연구 결과, 그룹운동군과 도수치료군은 가정운동군과 비교하여 치료 후 4 주부터 빠른 통증 감소, 어깨 관절운동범위의 향상, 기능적 상태의 회복을 보였다. 최종 12 주 추시 결과에서도 유의한 차이를 나 타냈다. 그룹운동군과 도수치료군과의 비교에서는 통증 척도와 관
절운동범위의 결과에서 유의한 차이가 없었지만, 어깨의 기능적 상 태를 평가하는 constant 점수는 그룹운동군에서 도수치료군보다 더 효과적으로 나타났다.

그룹운동군과 도수치료군이 가정운동군보다 빠른 통증 감소, 관 절가동범위의 향상을 나타냈으며, 그룹운동군과 도수치료군의 비교 에서는 치료 후 시기별로 유사한 결과를 보였다. 이러한 결과는 유착 성관절낭염 환자의 통증 경감과 관절운동범위 회복을 위해서는 초 기에 적극적인 치료 방법의 선택과 치료사의 감독 하에 수행되는 중 재가 도움이 된다는 것을 보여주는 것이라 판단된다. 추가적으로 그 룹운동군과 도수치료군의 통증, 관절가동범위의 빠른 회복은 지속 적인 능동 및 수동 관절운동이 유착된 관절낭에 역학적, 신경생리학 적 영향을 준 것으로 보인다. 관절 운동은 연골 기질과 활액 사이에 흐름을 증가시키고, 유착된 관절 조직의 유리화 및 관절낭 교원섬유 의 재배열과 같은 역학적 변화를 통해 관절 움직임을 회복시키는 것 으로 알려져 있다.1718 Leung 등 ${ }^{19}$ 은 유착성관절낭염 환자 30 명을 대상 으로 4 주간 기본 물리치료와 신장운동을 적용하여 유의한 통증 감 소와 관절가동범위의 향상을 보고하였고, 기본 물리치료 및 도수치 료를 포함한 운동치료는 마취하 도수교정이나 스테로이드 주사치료 와 같은 보다 침습적인 유착성관절낭염 치료와 비교 연구에서도 유 사한 임상적 결과를 보여 물리치료 중재방법들의 치료 효과를 지지 하고 있다..$^{20}$ 그러나 유착성관절낭염 환자 50 명을 대상으로 기본 물리 치료를 포함한 가정운동과 항염증성 약물치료를 병행하여 10년 간 장기 추시한 연구에서는 모든 대상자들이 통증과 관절가동범위의 제한 없이 일상 활동에 복귀하였다고 하였다. ${ }^{16}$ 본 연구와 다르게 가 정운동이 임상적 효과를 나타낸 선행 연구의 결과는 6 개월에서 2 년 간 지속되다가 점차적으로 사라지는 것으로 알려진 유착성관절낭염 의 자연 경과에 따른 것으로 풀이되며, 정확한 비교 분석을 위해서는 장기 추시의 필요성이 요구된다고 할수 있다.

본 연구의 결과 기능적 평가에서 그룹운동군은 빠른 기능 회복을 보였으며, 최종 추시 결과에서도 도수치료군과 가정운동군에 비해 우수한 치료 효과를 나타냈다. 그룹운동은 재활전문 물리치료사의 지도하에 서로 비슷한 증상을 가진 환자군이 모여 유착성관절낭염 
그룹운동을 수행하였다. 이러한 형태의 운동은 환자의 심리적 안정 을 도모할 뿐만 아니라 동료의식을 고취시켜 재활운동을 지속적으 로 수행할 수 있는 동기부여를 유발하게 된다. ${ }^{21}$ 환자들은 그룹운동 을 통해 유착성관절낭염의 임상 증상을 스스로 조절하며, 지속되는 통증과 기능제한에 능동적으로 대처하게 된다. 결과적으로 그룹운 동은 유착성관절낭염 환자의 자가 관리능력 향상과 의료시설 이용 을 감소시키고 자발적인 증상 조절 능력을 길러줄 것으로 판단된다. 견관절에 적용된 안정화 운동방법들은 근활성도의 변화를 이끌어 내고 기능적 향상을 가져온다. ${ }^{22,23}$ 그룹운동을 적용하여 만성 요통환 자를 대상으로 그룹운동을 시행한 결과 긍정적인 치료 효과를 얻을 수 있었고, 기본 물리치료의 횟수를 감소시켜 치료 비용에도 영향을 주었다고 보고하였다. ${ }^{24}$

본 연구에서 그룹운동군과 도수치료군에서 가정운동군과 비교하 여 빠른 치료 효과를 가져왔다. 하지만 제한점으로 비교적 짧은 추시 기간와 작은 규모의 표본을 대상으로 단일 의료 기관에서 수행된 무 작위 실험 연구이므로 유착성관절낭염 전체 환자에게 일반화 하기 는 어렵다. 앞으로 유착성관절낭염의 자연 경과에 따른 이환 기간을 고려하여 추가적인 장기 추시 연구가 필요할 것으로 생각된다.

\section{REFERENCES}

1. Wang K, Ho V, Hunter-Smith DJ et al. Risk factors in idiopathic adhesive capsulitis: a case control study. J Shoulder Elbow Surg. 2013;22,e24-e29.

2. Neviaser RJ, Neviaser TJ. The frozen shoulder: Diagnosis and management. Clin Orthop Relat Res. 1987;223:59-64.

3. Hand GC, Athanasou NA, Matthews T et al. The pathology of frozen shoulder. J Bone Joint Surg Br. 2007;89(7):928-32.

4. Shin SJ, Lee SY. Efficacies of corticosteroid injection at different sites of the shoulder for the treatment of adhesive capsulitis. J Shoulder Elbow Surg. 2013; 22(4):521-7.

5. Park KD, Nam HS, Lee JK et al. Treatment effects of ultrasound-guided capsular distension with hyaluronic acid in adhesive capsulitis of the shoulder. Arch Phys Med Rehabil. 2013;94(2):264-70.

6. John AG, Nicholas S, Bruce SM et al. Comparison of manipulation and arthroscopic capsular release for adhesive capsulitis: A systematic review. J Shoulder Elbow Surg. 2013;22(8):1135-45.

7. Dennis L, Brealey S, Rangan A et al. Managing idiopathic frozen shoulder: A survey of health professionals' current practice and research priorities. Shoulder Elbow. 2010;2(4):294-300.
8. Bart MB, Xavier S, Timothy DB. Arthroscopic release of adhesive capsulitis. J Shoulder Elbow Surg. 2004;13(2):180-5.

9. Jeremy L. Frozen shoulder contracture syndrome-Aetiology, diagnosis and management. Man Ther 2015;20(1):2-9.

10. Robinson CM, Seah KTM, Chee YH et al. Frozen shoulder. J Bone Joint Surg Br. 2012;94B(1):1-9.

11. Seo BD, Shin HS. The effect of self stretching exercise in patients with shoulder adhesive capsulitis. J Kor Soc Phys Ther. 2010;22(1):19-26.

12. Hanchard N, Goodchild L, Thompson J et al. Evidence-based clinical guidelines for the diagnosis, assessment and physiotherapy management of contracted shoulder: A quick reference summary. Physiother. 2012;98(2):117-20.

13. Sahrmann SA. Diagnosis and treatment of movement impairment syndromes. Elsevier. 2004;433-521.

14. Miller MD, Wirth MA, Rockwood CA. Thawing the frozen shoulder: The "patient" patient. Orthopedics. 1996;19(10):849-53.

15. Oh TY, Ha TY, Lee EJ et al. The effects of badminton on the shoulder and it's correlation with the shoulder pain and disability index. J Kor Soc Phys Ther. 2014;25(1):29-35.

16. Yian EH, Ramappa AJ, Arneberg O et al. The Constant Score in normal shoulders. J Shoulder Elbow Surg. 2005;14:128-33.

17. Noel G, Verbruggen LA, Barbaix E et al. Adding compression to mobilization in a rehabilitation program after knee surgery: A preliminary clinical observational study. Man Ther. 2000;5(2):102-7.

18. Mangus BC, Hoffman LA, Hoffman MA et al. Basic principles of extremity joint mobilization using a Kaltenborn approach. J Sport Rehabil. 2002;11(4):235-50.

19. Leung MS, Cheing GL. Effects of deep and superficial heating in the management of frozen shoulder. J Rehabil Med. 2008;40(2):145-50.

20. Carette S, Moffet H, Tardif J et al. Intra-articular corticosteroids, supervised physiotherapy or a combination of the two in the treatment of adhesive capsulitis of the shoulder: A placebo controlled trial. Arthritis Rheum. 2003;48(3):829-38.

21. Russel S, Jariwala A, Colon R et al. A blinded, randomized, controlled trial assessing conservative management strategies for frozen shoulder. J Shoulder Elbow Surg. 2014;23(4):500-7.

22. Park HJ, Oh TY. Effects of closed chain exercise on activities of shoulder girdle muscles in 60's. J Kor Soc Phys Ther. 2015;27(4):246-51.

23. Yang DJ, Uhm YH, Kim JH. The biofeedback scapular stabilization exercise in stroke patients effect of muscle activity and function of the upper extremity. J Kor Soc Phys Ther. 2015, 27(5):325-31.

24. Carr JL, Klaber Moffett JA, Howarth E et al. A randomized trial comparing a group exercise programme for back pain patients with individual physiotherapy in a severely deprived area. Disabil Rehabil. 2005;27(16): 929-37. 